\title{
Distribution of feet pressure on ground and maintaining body balance among 8 -10-year-old children with and without external load application
}

\author{
JAROSŁAW JASZCZUR-NOWICKI ${ }^{1 *}$, JOANNA M. BUKOWSKA ${ }^{1}$, DARIUSZ KRUCZKOWSKI ${ }^{2}$, \\ MAGDALENA PIENIĄŻEK ${ }^{3}$, GRZEGORZ MAŃKO ${ }^{4}$, MICHA£ SPIESZNY ${ }^{5}$ \\ ${ }^{1}$ Department of Tourism, Recreation and Ecology, University of Warmia and Mazury in Olsztyn, Poland. \\ ${ }^{2}$ University of Humanities and Economics in Elbląg, Poland. \\ ${ }^{3}$ Department of Rehabilitation in Internal Diseases, Faculty of Rehabilitation, University of Physical Education in Krakow, Poland. \\ ${ }^{4}$ Faculty of Health Sciences, Department of Biomechanics and Kinesiology, Jagiellonian University Medical College in Kraków, Poland. \\ ${ }^{5}$ Institute of Sport Sciences, Faculty of Physical Education and Sports, University of Physical Education in Krakow, Poland.
}

Purpose: The aim of this study was to analyse the impact of applying an external load on the distribution of pressure on the plantar side of the foot and maintaining body balance, using the podobarographic platform. Methods: The study was conducted on 130 school children aged 8-10: girls $(n=68$, body mass $=22.8 \pm 6.0 \mathrm{~kg}$, body height $=129.3 \pm 7.5 \mathrm{~cm})$ and boys $(n=62$, body mass $=31.1 \pm 6.5 \mathrm{~kg}$, body height $134.4 \pm 7.3 \mathrm{~cm}$ ). The study involved 2 trials. At first, children stood on the platform assuming a natural position. Then, they put on a 5-kg backpack and stood on the platform once more. Results: The results indicate that after backpack loading, for the total research group of girls and boys, statistically significant differences were found in the distribution of foot force on the ground in the left forefoot $(p=0.008)$, metatarsus $(p=0.000)$ and heel areas $(p=0.002)$. While in the right foot, these differences were noted for the forefoot $(p=0.024)$ and metatarsus $(p=0.000)$. The results of balance testing were also statistically significant. They concerned measurements of the body barycentre area (cop-bars $p=0.003)$, the barycentre area of the left foot (1-bars $p=0.034)$ and the parameter comparing distance to surface ratio (cop-lsf $p=0.000$ ). Conclusions: It may be concluded that prolonged overloading with backpacks affects movement patterns, which may further lead to the acquisition and consolidation of postural defects.

Key words: foot, ground pressure, body balance, children, backpack

\section{Introduction}

School is an important social institution that covers about $20 \%$ of active members of society. Many authors indicate that overloaded backpacks can lead to the development of back pain and other injuries of the musculoskeletal system among children and adolescents [7]. School children are teenagers who experience a period of accelerated growth and development of the skeletal and soft tissues. Their spinal structures are therefore different than adults', they are more susceptible to disorders resulting from external factors.
Moreover, external forces, such as load transfer, can also affect the growth, development and maintenance of positioning the human body [22]. The non-standard weight of a backpack increases the frequency of lowering the arms, which further leads to kyphosis and lordosis in primary school students. This is a threat to the physical health of our future society. Therefore, parents, teachers and health care professionals should provide students with the training necessary to safely carry bags and backpacks [24].

In the existing subject-literature, studies based on epidemiological, physiological and biomechanical approaches, in which it is confirmed that backpacks

\footnotetext{
* Corresponding author: Jarosław Jaszczur-Nowicki, Department of Tourism, Recreation and Ecology, University of Warmia and Mazury in Olsztyn, ul. Oczapowskiego 5, 10-719 Olsztyn, Poland. E-mail: j.jaszczur-nowicki@uwm.edu.pl

Received: July 13th, 2020

Accepted for publication: September 17th, 2020
} 
weighing $10-15 \%$ of body mass constitute a justified upper limit, can be found. The very development of improper posture and its control is associated with abnormal sensory sensations, lack of proper postural tension or correct posture and movement patterns, as well as with incorrect mutual innervation. It disrupts the central stabilisation of a child's body and their posture structure [4]. The child's dimensions, mass and proportions change during ontogenesis, shaping of muscles and movement pattern. Locomotion is the result of coordinated actions of about 10 muscles involving various joints. The lower limbs and other parts of the body, through constant repetition of specific coordination patterns between them, cause gait to be a cyclical physical activity [5].

The human foot is an significant static-dynamic part of the musculoskeletal system. On the one hand, it is a supporting element, and in static conditions, it allows the body to maintain balance in space, while on the other, it is a driving mechanism that provides the body with propulsion during movement. Therefore, the foot, thanks to its specific design, absorbs shocks arising during locomotive movements, protecting the nervous system, spine and internal organs against micro-injuries resulting from everyday activities. Analysis of the existing literature shows that already at the end of the 1 st year of life, when the child begins to load their feet, dynamic development of the longitudinal arch occurs [12].

In stabiliographic research from 2010 [21], significant relationships were demonstrated between postural defects found in the sagittal plane and the average foot load point. Stabilography is one of the most common methods for assessing posture stability, defined as the ability to maintain balance. It involves analysing the resulting ground reaction forces caused by feet pressure while standing. The way of maintaining balance is evidence of the ability to maintain motor coordination [11]. Balance may be shaped according to age because there is a strong correlation between this variable and balance results. In older children, body mass and height may partially affect balance. Agerelated changes in balance control may be associated with the development of the visual, vestibular and somatosensory systems [10].

In foot diagnostics, traditional methods can be distinguished: orthopaedic - based on foot examination and foot fitness tests, anthropometric methods - based on length, height, width and circumference measurements, and plantoconturographic methods - most frequently based on ink prints. Computed tomography and magnetic resonance imaging are also used in foot examinations, however, the most com- mon electronic print is the plantar surface of the foot, but more and more often, various types of podobarographic platforms are being used to conduct this type of testing [8]. Balance evaluation can be performed by static stabilisation, which deals with the registration of involuntary changes in the location of the resultant pressure forces on the posture plane of a person standing freely on a stabilographic platform. As a result of registration, the trajectory of this point is obtained (in the literature, this point is called COP - centre of pressure). Modern technologies make it possible to examine the distribution of forces on the plantar side of the foot and stabilographic examination in 1 trial using a podobarographic mat [9]. Such a mat was used in this study.

The aim of the study was to determine the impact of external load on foot force distribution on the ground among 8-10-year-old girls and boys. Assessment of the maintenance of body balance by the subjects was also the objective of the study. Conducting such an analysis was possible by identifying the differences in the distribution of forces in the various areas of the foot affecting the surface and maintaining the balance of the body in children with and without a school backpack load.

\section{Materials and methods}

The research included 130 randomly selected kids: 68 girls and 62 boys aged $8-10$. The children participating in the research were students of three Gdańsk public schools and they participated in an educational and preventive program, in which one of the goals was to shape pro-health attitudes of students in the field of proper development of motor skills and body posture. The average age of the entire group being surveyed is $8.9 \pm 0.8$ years, the average age of boys is $9.2 \pm 0.7$ years and the girls $-8.6 \pm 0.8$ years. The boys were heavier and taller than the girls, their weight was $31.13 \pm 6.5 \mathrm{~kg}$ and body height was $134.4 \pm 7.3 \mathrm{~cm}$, girls - respectively: $27.8 \pm 6.0 \mathrm{~kg}$ and $129.3 \pm 7.5 \mathrm{~cm}$. Parents and the school management gave their written consent to the participation of children in the study. The research was conducted on the basis of the consent of the Commission for Ethics of Scientific Research of the University of Warmia and Mazury in Olsztyn (Decision No. 9/2018).

For testing, the E.P.S. R1 podobarorographic mat (Letsens Group, Letsens S.R.L. Via Buozzi, CastelMaggiore; Italy) was used. This is a diagnostic device used for assessing foot defects in static and dynamic 
conditions. It enables the researchers to examine the distribution of foot forces on the surface and body balance. The mat is equipped with sensors that collect measurements for 20 seconds and transfer them to a computer using the Biomech Studio program (Biomech Studio 2.0 manual).

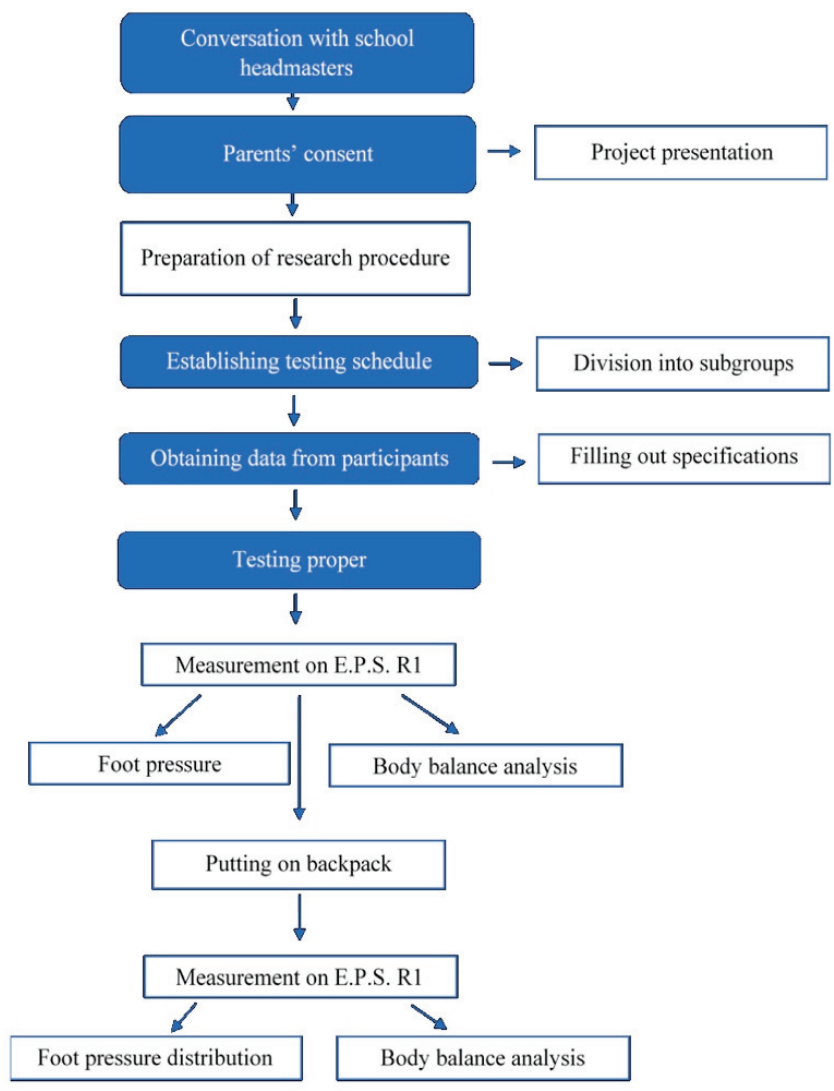

Fig. 1. Schematic of research procedure
The analyses were carried out in May 2019 in Gdańsk. Measurements were taken in the morning hours $(10.00-12.00)$. The test pattern is illustrated in detail in Fig. 1.

\section{Statistical Analysis}

The Statistica 13.0 program was used for statistical calculations. The Mann-Whitney-Wilcoxon test (also known as the Mann-Whitney test or sometimes the Wilcoxon Rank Sum Test for two samples, or simply the Wilcoxon test for two samples). Due to the absence of normal distribution of the measurement results in the research group, the non-parametric test function was used. Therefore, non-parametric statistical functions were used in further analysis and inference. The median was applied as the main measure of average study sample value, and quartile 1 and 3 for threshold dispersion. For the purposes of analysing the statistical significance of differences between the results of measurements during rest and after loading with a 5-kg backpack for girls and boys, the Wilcoxon test was used, while for differences in the results of observation between both study sample, the MannWhitney $U$-test was applied.

\section{Results}

Descriptive statistics of foot parameters in resting conditions for girls and boys indicate a similar load on the forefoot and heel within $43-47 \%$ (Table 1). The average value in both samples allows to notice a slightly

Table 1. Significance of differences between measurements at rest and with backpack load for podological test for both study samples

\begin{tabular}{|c|c|c|c|c|c|c|c|c|c|c|c|c|}
\hline \multirow[b]{2}{*}{ 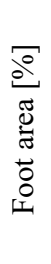 } & \multicolumn{6}{|c|}{ Left foot } & \multicolumn{6}{|c|}{ Right foot } \\
\hline & $\begin{array}{l}\vec{y} \\
ٍ \\
0 \\
0 \\
0 \\
0 \\
0 \\
0 \\
0\end{array}$ & $\begin{array}{l}\tilde{Z} \\
0 \\
0 \\
0 \\
0 \\
0 \\
0 \\
0 \\
0 \\
0\end{array}$ & 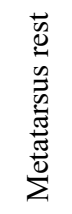 & 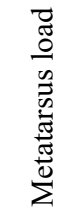 & 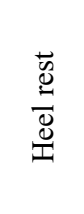 & 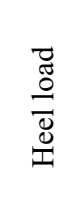 & 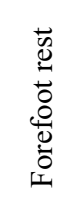 & 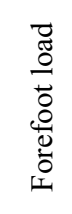 & 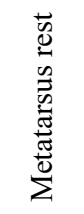 & 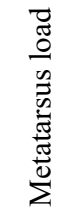 & 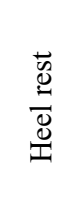 & 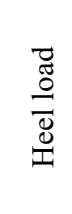 \\
\hline \multicolumn{13}{|c|}{ girls $(n=68)$} \\
\hline $\mathrm{Me}$ & 45.8 & 44.5 & 4.5 & 9.3 & 44.4 & 41.6 & 49.5 & 47.3 & 8.1 & 13.5 & 39.3 & 38.2 \\
\hline $\mathrm{Q}_{1}$ & 40.2 & 40.3 & 1.7 & 2.9 & 38.7 & 38.1 & 45.3 & 42.1 & 1.8 & 3.4 & 34.3 & 33.7 \\
\hline $\mathrm{Q}_{3}$ & 51.5 & 50.7 & 13.9 & 20.7 & 51.3 & 47.5 & 56.2 & 53.1 & 19.2 & 22.7 & 43.1 & 44.3 \\
\hline$p$ & \multicolumn{2}{|c|}{0.040} & \multicolumn{2}{|c|}{0.000} & \multicolumn{2}{|c|}{0.060} & \multicolumn{2}{|c|}{0.007} & \multicolumn{2}{|c|}{0.002} & \multicolumn{2}{|c|}{0.917} \\
\hline \multicolumn{13}{|c|}{ boys $(n=62)$} \\
\hline $\mathrm{Me}$ & 47.3 & 46.1 & 5.6 & 11.1 & 43.4 & 42.3 & 50.2 & 49.9 & 6.6 & 9.8 & 39.6 & 38.1 \\
\hline $\mathrm{Q}_{1}$ & 42.6 & 41.5 & 2.1 & 4.1 & 38.3 & 36.8 & 44.9 & 44.7 & 2.2 & 4.4 & 36.0 & 34.5 \\
\hline $\mathrm{Q}_{3}$ & 53.0 & 52.0 & 17.8 & 19.6 & 49.3 & 46.0 & 54.9 & 55.9 & 17.2 & 17.9 & 43.8 & 41.2 \\
\hline$p$ & \multicolumn{2}{|c|}{0.081} & \multicolumn{2}{|c|}{0.001} & \multicolumn{2}{|c|}{0.014} & \multicolumn{2}{|c|}{0.842} & \multicolumn{2}{|c|}{0.019} & \multicolumn{2}{|c|}{0.049} \\
\hline
\end{tabular}

Legend: $\mathrm{Me}$ - the middle average of a sample, $\mathrm{Q}_{1}, \mathrm{Q}_{3}$ - extreme quartiles, $p$ - statistical significance. 
higher load on the forefoot by approx. $4 \%$ in boys and $1.5 \%$ in girls. The average pressure on the metatarsus in both research groups, depending on the left or right foot, was about $4.5-8.0 \%$.

Analysing the differences between resting state and backpack load measurements among the total group of girls and boys being studied, significant differentiation was noted regarding all areas of the left foot (forefoot, metatarsus and heel) and for the forefoot and metatarsus of the right foot (Table 1). When analysing statistical differences between the values for the groups of girls and boys, no significant results were recorded both at rest or after loading ( $p \geq 0.05)$. Subjecting the differences between resting measurements and after backpack loading to statistical analysis, a number significant differences were noted (Table 1). In the research group of girls, significant differences were noted for the forefoot and metatarsus in both feet, while among the examined boys, for the metatarsal and heel areas.

Similarly as in the case of podological examination, subjecting the results of posturographic examination to mathematical analysis, significant dispersion of the measured values was noted. The values of dispersion measures ranged from a several dozen to $340 \%$ as in the case of the left foot deflection area (1-bars). No features of normal distribution were found for selected parameters, therefore, nonparametric functions were used in statistical proceedings.

When assessing the average values of posturographic test parameters in resting conditions and after loading, for the group of girls, differences were found allowing to state the existence of load impact on the values of body posture deflection (Table 2 ).

A particular increase in the measured values was observed for the parameters specifying the values of deflection areas for cop-bars - total posture, r-bars - left foot and 1-bars - right foot (by 96, 132 and $211 \mathrm{~mm}^{2}$, respectively). A similar analysis was conducted in the group of boys (Table 3 ). In this case, the differences in the average measured values of all parameters were not significant. For the parameters of deflection surface areas, they totalled: cop-bars $=4.7$, r-bars $=4.7$ and l-bars $=11.8$. The average value of the parameter, which is the ratio of the extreme deflection distances to the total area in both groups, showed differences of $72-75 \%$.

Conducting statistical assessment of the differences between values of posturographic examination parameters at rest and after loading among the group of girls, significant differences were noted for the majority (Table 3 ). These regarded cop-bars, r-bars and l-bars as well as the parameter of the distance to surface area (cop-lsf). Similar assessment in the boys' group revealed significant differences only for the cop-lsf parameter. When comparing both examined research group of girls and boys, significant differences were confirmed for cop-bars, 1-bars and cop-lsf. An attempt to evaluate the statistical differences in resting conditions and after backpack loading between the group of examined girls and boys did not reveal any significant differences.

Table 2. Descriptive statistic of the posturographic test among the examined research group at rest and after loading with backpack (5 kg)

\begin{tabular}{|c|c|c|c|c|c|c|c|c|c|c|c|c|}
\hline \multirow[b]{2}{*}{ 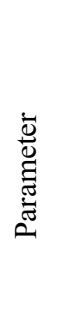 } & \multicolumn{6}{|c|}{ Measurement at rest } & \multicolumn{6}{|c|}{ Measurement after loading } \\
\hline & 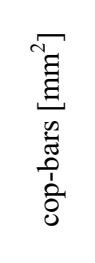 & 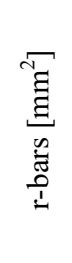 & 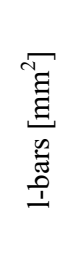 & 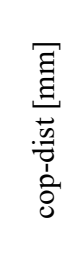 & 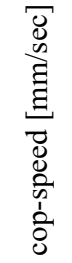 & $\begin{array}{l}\frac{w}{n} \\
\frac{1}{\dot{0}} \\
\frac{\delta}{0}\end{array}$ & 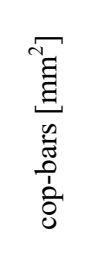 & 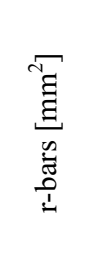 & 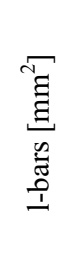 & 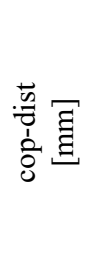 & 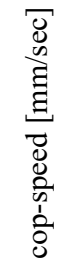 & $\frac{\tilde{n}}{\frac{\pi}{1}}$ \\
\hline \multicolumn{13}{|c|}{ Population of girls $(n=68)$} \\
\hline $\mathrm{Me}$ & 152.8 & 41.5 & 21.0 & 170.3 & 8.6 & 1.1 & 190.9 & 38.1 & 27.3 & 178.1 & 8.9 & 0.9 \\
\hline $\mathrm{Q}_{1}$ & 93.9 & 22.0 & 11.7 & 145.4 & 7.4 & 0.8 & 111.3 & 25.9 & 15.7 & 154.4 & 7.7 & 0.5 \\
\hline $\mathrm{Q}_{3}$ & 241.1 & 71.4 & 41.5 & 205.8 & 10.3 & 1.7 & 380.1 & 108.6 & 63.9 & 219.4 & 11.2 & 1.6 \\
\hline \multicolumn{13}{|c|}{ Population of boys $(n=62)$} \\
\hline $\mathrm{Me}$ & 131.8 & 32.4 & 25.3 & 170.5 & 8.6 & 1.3 & 154.7 & 41.1 & 25.9 & 167.4 & 8.4 & 1.1 \\
\hline $\mathrm{Q}_{1}$ & 65.5 & 14.1 & 9.7 & 137.4 & 6.9 & 0.7 & 91.9 & 15.5 & 15.3 & 138.9 & 7.0 & 0.7 \\
\hline $\mathrm{Q}_{3}$ & 238.3 & 86.6 & 64.2 & 201.8 & 9.9 & 2.2 & 270.3 & 92.2 & 63.2 & 191.7 & 9.6 & 1.5 \\
\hline
\end{tabular}

Legend: $\mathrm{Me}$ - the middle average of a sample, $\mathrm{Q}_{1}, \mathrm{Q}_{3}$ - extreme quartiles, cop-bars - total surface area of deflections from body's centre of gravity, 1-bars - surface area of left foot, r-bars - surface area of right foot, cop-dist - distance between extreme deflections, cop-speed - mean speed of deflections, cop-lsf - ratio of distance between extreme deflection to deflection area. 
Table 3. Significance of differences between measurement at rest and loading with backpack for the parameters of posturographic testing for both study samples

\begin{tabular}{|c|c|c|c|}
\hline \multirow[b]{2}{*}{ Parameter } & \multicolumn{3}{|c|}{$\begin{array}{c}\text { Population of girls }(n=68) \\
\text { and boys }(n=62)\end{array}$} \\
\hline & $T$ & $Z$ & $p$ \\
\hline cop-bars $\left[\mathrm{mm}^{2}\right]$ & 2994.000 & 2.936 & 0.003 \\
\hline r-bars $\left[\mathrm{mm}^{2}\right]$ & 3514.500 & 1.727 & 0.084 \\
\hline 1-bars $\left[\mathrm{mm}^{2}\right]$ & 3346.000 & 2.118 & 0.034 \\
\hline cop-dist [mm] & 3868.000 & 0.763 & 0.446 \\
\hline cop-speed $[\mathrm{mm} / \mathrm{sec}]$ & 3426.000 & 1.260 & 0.208 \\
\hline cop-lsf & 2284.000 & 3.638 & 0.000 \\
\hline \multicolumn{4}{|c|}{ Population of girls $(n=68)$} \\
\hline cop-bars $\left[\mathrm{mm}^{2}\right]$ & 704.000 & 2.866 & 0.004 \\
\hline r-bars $\left[\mathrm{mm}^{2}\right]$ & 846.500 & 1.995 & 0.046 \\
\hline 1-bars $\left[\mathrm{mm}^{2}\right]$ & 820.000 & 2.157 & 0.031 \\
\hline cop-dist [mm] & 895.000 & 1.699 & 0.089 \\
\hline cop-speed $[\mathrm{mm} / \mathrm{sec}]$ & 833.500 & 1.908 & 0.056 \\
\hline cop-lsf & 609.500 & 2.573 & 0.010 \\
\hline \multicolumn{4}{|c|}{ Population of boys $(n=62)$} \\
\hline cop-bars $\left[\mathrm{mm}^{2}\right]$ & 804.000 & 1.209 & 0.227 \\
\hline r-bars $\left[\mathrm{mm}^{2}\right]$ & 912.000 & 0.452 & 0.651 \\
\hline 1-bars $\left[\mathrm{mm}^{2}\right]$ & 861.000 & 0.810 & 0.418 \\
\hline cop-dist [mm] & 856.500 & 0.639 & 0.523 \\
\hline cop-speed $[\mathrm{mm} / \mathrm{sec}]$ & 830.500 & 0.194 & 0.847 \\
\hline cop-lsf & 542.000 & 2.589 & 0.010 \\
\hline
\end{tabular}

Legend: cop-bars - total surface area of deflections from body's centre of gravity, 1-bars - surface area of left foot, r-bars - surface area of right foot, cop-dist - distance between extreme deflections, cop-speed - mean speed of deflections, cop-lsf - ratio of distance between extreme deflection to deflection area

\section{Discussion}

According to Yamato et al. [23], there is no convincing evidence that the use of school backpacks increases the risk of back pain. There is some evidence that feeling the weight of an object is associated with back pain. Children aged 11-14 report back pain, most of whom attribute their pain to wearing a school backpack [15]. When the load of a backpack is greater than the load capacity of muscle groups, the spine is overloaded, which can cause changes in posture, pain or dysfunctions. Since wearing a backpack with school supplies is a daily routine that is repeated over the years, special care should be devoted to avoiding postural changes that could become permanent in the mid- to long-term and thus, endanger health [17].

The results presented in this paper confirm the above thesis also assumed by other authors. Just putting on a 5-kg backpack changes a child's posture, including the distribution of plantar forces on the ground. Prolonged periods of carrying a heavy backpack leads to consolidation of these changes. Other authors have also dealt with the issue of pressure on the plantar surface with the application of an external load. In their study, Pau et al. [16] analysed maps of plantar pressure in static conditions among 359 primary school children (6-10 years of age). Statistically significant differences depended on the presence of the backpack $(p<0.01)$. The largest modifications were noted in the metatarsal area (with an increase of about $16 \%$ for the highest load), followed by the forefoot $(+9 \%)$, the rear part of the foot remained practically constant regardless of the assumed load size. Statistical analysis showed significant impact of the backpack only on the metatarsal and forefoot areas ( $p<0.01$ in both cases). In research carried out on a general research group for the purposes of this study, a statistically significant difference for the metatarsal area, both in the right and left foot, was recorded at $p=0.000$. However, for the forefoot area, these values were $p=0.024$ and $p=0.008$ for the right and left legs, respectively.

Children, both girls and boys, from London schools aged 7-11 took part in a study by Cousins et al. [6]. Only the students who did not have orthopaedic, neurological and/or musculoskeletal problems were included in the study. Participants were classified according to body mass: 22 obese, 22 overweight and 56 children within the norm. During the experiment, students had to walk a 5-meter section, in the middle of which a podobarographic platform was placed. Subjects covered the marked section of the route barefoot, asssuming a natural gait pattern and with the speed of their choice. Analysis of the results showed that children with excessive body mass demonstrated significantly $(p<0.05)$ higher metatarsal load. These results indicate that not only the applied load used in the experiment carried out by the authors of this work, but also excessive body mass cause the largest statistically significant differences to be noticeable in the metatarsal area.

The cited examples confirm the thesis indicated by Moslemi et al. [13] stating that the incidence of posture structure disorders is quite high among primary school children and is closely related to some ergonomic parameters, such as weight and type of backpack. Bibro et al. [3] dealt with the issue of the impact of strength training on the distribution of plantar pressure. The research was conducted among 60 students. The males were divided into 2 equal groups of 30 . Group 1, subjected to training, completed the exercise at a gym within 60 minutes, including lower limb exercises. The training consisted of 7 complex exercises 
performed in accordance with the principles of strength training. The weight selection was individual, the repetition range was from 8 to 12 maximum repetitions, performed in 3 or 4 series. The intervals between the series lasted about 3-4 minutes. Group 2 - the control - spent the time between consecutive tests passively, in a seated position. In both groups, there was a tendency towards increasing forefoot load in the 2nd trial. After the training session, the examined males demonstrated significantly increased load on the lateral forefoot of the left foot and the load on the medial forefoot of both feet. Strength training of the lower limbs caused a significant reduction in both lateral load as well as on the medial side of the right hindfoot.

In the research by Varga et al. [19], it was shown that with age, the longitudinal arch changes, which increases surface and concavity. Compared with the results presented in this paper and the above-mentioned results obtained by other authors, it may be indicated that the application of external load in various forms, regardless of age and foot convexity, significantly affects load on the forefoot area. Alghadier [1] showed that wearing a backpack significantly affects foot load patterns (peak plantar pressure, peak plantar strength and contact area). The difference (SD) in maximal support pressure was $11.2(12.5) \mathrm{kPa}$, peak plantar strength $3.7(3.5) \mathrm{N}$ and contact surface, $1.6(2.9) \mathrm{cm}^{2}$. The same conclusions as those reached in this study were found by Vieira et al. [20], who conducted dynamic research among 117 high school students. The cited results showed that the values regarding both the displacement of the COP and its average speed were higher when using an external load in the form of a backpack than without its use. The issue of backpack weight among students in Chennai was dealt with by Suresh et al. [18]. The results of their research showed that the backpack load should be reduced to $5 \%$ of body mass.

Barbosa et al. [2] also dealt with the problem of surface reaction, examining 21 children (12 from grade 9 and 9 from grade 5). The backpacks of the younger children weighed $5 \mathrm{~kg}$ and for those from higher grades, $4.5 \mathrm{~kg}$. In both cases, during walking and running, the use of the backpack significantly affected all of the analysed variables. Zhou et al. [25] examining 100 healthy primary school students (aged 7-12) when walking with a backpack load of $5,10,15,20$ and $25 \%$ of body mass, came to the conclusion that the increase in backpack weight has a limited effect on COP, and students can cope with the risk of balance loss resulting from increased load. They noticed that to maintain balance control, students adjust their posture by eliminating risk factors for balance loss due to load. When increasing the load had huge im- pact on body posture, a load of $15 \%$ body mass may be considered a safe value. The results presented above are in contradiction with the analysis conducted by the authors of this work, who noted statistically significant differences regarding cop-bars.

Analysing the literature and the results of the authors' research on the impact of using an external load in the form of a school backpack, statistically significant differences were expected. In comparative assessment, a negative change in the convexity of the foot was undeniably noted, as well as worse postural stability among the examined girls and boys, resulting from the applied load.

\section{Conclusions}

Considering a child's physical development, it is not advisable for students to wear overloaded backpacks on their way to and back from school or going to and from classes. As resulted from the tests conducted, a possible overloaded pattern of movement, manifested in the static effects of body posture, may be a factor in the acquisition and consolidation of body posture irregularities and defects within the foot towards a flat foot. School children and teenagers spend a lot of time at school. Moving from home to school and back also takes a certain amount of time. Providing them with a safe and healthy environment can reduce their susceptibility to injury, chronic health conditions and their complications. Backpacks and school supplies are worn by children in different ways, therefore, the weight and the way they are taken over by the students should be considered as an important issue.

\section{References}

[1] Alghadier M., The effect of backpack weight on dynamic foot-loading patterns in Saudi school boys aged 7 to 12 years, Physiotherapy, 2015, 101: e51-e52, DOI: 10.1016/ j.physio.2015.03.169.

[2] Barbosa J.P., Marques M.C., Neiva H.P., Esteves D., Alonso-Martínez A.M., IzQUierdo M., Marinho D.A., Effects of backpacks on ground reaction forces in children of different ages when walking, running, and jumping, Int. J. Environ. Res. Public Health, 2019, 16 (24), 5154, DOI: 10.3390/ijerph16245154.

[3] Bibro M., Drwal A., Jankowicz-SzymańSKa A., Ocena wysklepienia oraz rozkladu sit nacisku podeszwowej strony stóp młodych mężczyzn pod wptywem treningu siłowego kończyn dolnych (in Polish), [The assessment of the effect of strength training of lower limbs on arching and forces distribution of the sole in young men], Health Prmot. Phys. Act., 2018, 4 (3), 7-11. DOI: 10.5604/01.3001.0012.8372. 
[4] BienieK K., WilczyŃSKi J., Analysis of the relationship between body posture and postural stability in girls aged 10-12 years, Stud. Med., 2019, 35 (1), 55-60, DOI: 10.5114/ ms.2019.84052.

[5] BŁASZCZYK J.W., Biomechanika lokomocji (Biomechanics of locomotion), [in:] J.W. Błaszczyk, Podstawowe parametry chodu, Biomechanika kliniczna podręcznik dla studentów medycyny i fizjoterapii (Basic gait parameters, Clinical Biomechanics, a textbook for students of medicine and physiotherapy), PZWL, Warszawa, 2004, 243-265 (in Polish).

[6] Cousins S.D., Morrison S.C., Drechsler W.I., Foot loading patterns in normal weight, overweight and obese children aged 7 to 11 years, J. Foot Ankle Res., 2013, 6 (1): 36, DOI: 10.1186/1757-1146-6-36.

[7] Francisco C., Silva J., Sousa S., Gonçalves D., Azevedo N., Rodrigues L., PACHeCo G., Association between school backpack weight and the appearance of postural changes in school-age children, Eur. J. Public Health, 2019, 29, 1, ckz034.068, DOI: 10.1093/eurpub/ckz034.068.

[8] JaszCZUR-Nowicki J., KRUCZKOwSKi D., BuKowsKa J.M., Analysis of the distribution of foot force on the ground before and after a kinaesthetic stimulation, Journal of Kinesiology and Exercise Sciences (JKES), 2019; 86 (29), 19-27, DOI: 10.5604/01.3001.0014.1273.

[9] Jaszczur-Nowicki J., Bukowska J.M., Kruczkowski D., SPIESZny M., PIENIĄŻeK M., MAŃKO G., Analysis of students' foot pressure distribution on the ground, as well as their body balance before and after exercise, Physical Education of Students (PES), 2020, 24 (4), 194-204, DOI: $10.15561 / 20755279.2020 .0402$.

[10] Mańko G., Kruczkowski D., Niźnikowski T., Perliński J., CHANTSOUlis M. et al., The effect of programed physical activity measured with levels of body balance maintenance, Med. Sci. Monit., 2014, 20, 1841-1849, DOI: 10.12659/ MSM.889521.

[11] MichNiK R., JURKOJC J., WODARSKi P., GZIK M., JOCHYMCZYK-WoźNIAK K., BIENIEK A., The influence of frequency of visual disorders on stabilographic parameters, Acta Bioeng. Biomech., 2016, 18 (1), 25-33, DOI: 10.5277/ABB-002012014-04.

[12] Mickle K.J., SteEle J.R., MunRo B.J., The feet of overweight and obese young children: are they flat or fat?, Obesity, 2006, 14 (11), 1949-1953, DOI: 10.1038/oby.2006.227.

[13] Moslemi S., Mohammadi S., Hosseininejad M., Mohtasham S., Assessment of backpacks parameters and postural structure disturbances association among Iranian children, Int. J. Pediatr., 2018, 6 (3), 7413-7419, DOI: 10.22038/IJP.2017.24958.2111.

[14] Mrozkowiak M., Uwarunkowania wybranych parametrów postawy ciała dzieci i młodzieży oraz ich zmienność w świetle mory projekcyjnej (Determinants of selected parameters of body posture of children and adolescents and their variability in the light of the projection moire), Oficyna Wydawnicza Uniwersytetu Zielonogórskiego, Zielona Góra 2010, 63-178 (in Polish).

[15] Neuschwander B.T., Cutrone J., Macias R.B., Cutrone S., MuRTHy G. et al., The effect of backpacks on the lumbar spine in children, Spine, 2010, 35 (1), 83-88, DOI: 10.1097/ BRS.0b013e3181b21a5d.

[16] Pau M., Corona F., Leban B., PaU M., Effects of backpack carriage on foot-ground relationship in children during upright stance, Gait Posture, 2011, 33 (2), 195-199, DOI: 10.1016/j.gaitpost.2010.10.096.

[17] Rodrigues S., Monebelo M., Teodori R.M., Plantar force distribution and pressure center oscillation in relation to the weight and positioning of school supplies and books in student's backpack, Rev. Bras. Fisioter., 2008, 12 (1), 43-48, DOI: $10.1590 /$ S1413-35552008000100009.

[18] Suresh C., Sangeetha S., Premavathy D., Knowledge, prevalence, and awareness of postural effects due to heavy backpacks in college students, Drug. Invent. Today, 2019, 12 (10), 2153-2156.

[19] Varga M., Price C., Morrison S.C., Three-dimensional foot shape analysis in children: a pilot analysis using three-dimensional shape descriptors, J. Foot Ankle Res., 2020, 13 (1), 1-9, DOI: 10.1186/s13047-020-0373-7.

[20] Vieira M.F., Lehnen G.C., Noll M., Rodrigues F.B., DE AVElAR I.S., DA CostA P.H.L., Use of a backpack alters gait initiation of high school students, J. Electromyogr. Kines., 2016, 28, 82-89, DOI: 10.1016/j.jelekin.2016.03.008.

[21] Wliczyński J., Postawa ciała w plaszczyźnie strzatkowej a średni punkt obciązenia stóp u dziewczą $i$ chtopców $w$ wieku 12-15 lat (Sagittal body posture and mean foot load point in girls and boys aged 12-15 years), Uniwersytet Jana Kochanowskiego w Kielcach, 2010, 28-34 (in Polish).

[22] Wojtków M., Szkoda-Poliszuk K., Szotek S., Influence of body posture on foot load distribution in young school-age children, Acta Bioeng. Biomech., 2018, 20 (2), 101-107, DOI: 10.5277/ABB-01079-2018-01.

[23] Yamato T.P., Maher C.G., Traeger A.C., Williams C.M., KAMPER S.J., Do schoolbags cause back pain in children and adolescents? A systematic review, Br. J. Sports Med., 2018, 52, 1241-1245, DOI: 10.1136/bjsports-2017-098927.

[24] Zakeri Y., Baraz S., Gheibizadeh M., SaidKhani V., Relationship between backpack weight and prevalence of lordosis, kyphosis, scoliosis and dropped shoulders in elementary students, Int. J. Pediatr., 2016, 4(6), 1859-1866, DOI: 10.22038/ ijp.2016.6846.

[25] ZHOU N., CHEN W., ZHOU J., YANG L., Influence of the increasing weight of the backpack on the balance of movement to primary school students, Rev. Piel. Incaltaminte, 2018, 18, 123-130, DOI: 10.24264/lfj.18.2.7. 